\title{
Bangladesh: RH curriculum enhances vocational students' knowledge and behavior
}

Frontiers in Reproductive Health

Follow this and additional works at: https://knowledgecommons.popcouncil.org/departments_sbsr-rh

Part of the Demography, Population, and Ecology Commons, Family, Life Course, and Society Commons, International Public Health Commons, Medicine and Health Commons, and the Women's Health Commons How does access to this work benefit you? Let us know!

\section{Recommended Citation}

"Bangladesh: RH curriculum enhances vocational students' knowledge and behavior," FRONTIERS OR Summary no. 62. Washington, DC: Population Council, 2007. 


\section{Bangladesh Youth}

OR Summary 62

\section{RH Curriculum Enhances Vocational Students' Knowledge and Behavior}

When reproductive health education was integrated with vocational training programs in Bangladesh, students' knowledge, attitudes, and life skills related to reproductive health improved. The intervention is being implemented on a wider scale at vocational training centers.

\section{Background}

In 2004 the Population Council's FRONTIERS Program and the Bangladesh Ministry of Youth and Sports collaborated on an intervention to introduce reproductive health education into government-run vocational training courses. The training, offered to males and females aged 15-30, includes livestock husbandry, electronics, and secretarial work. This intervention built upon the positive results of the 1999 Bangladesh Youth Reproductive Health Study, which introduced a life skills curriculum into secondary schools (see Bhuiya et al. 2004).

This 10-hour interactive reproductive health curriculum was modified to suit the older adolescents and youth attending the vocational training courses. It included the topics of reproductive biology, family planning, pregnancy, sexually transmitted infections, critical thinking, and negotiation skills. The curriculum employed interactive and lively methods such as stories, quizzes, riddles, debates, visuals, and discussions.

The curriculum was tested in five of the 47 residential training centers. Two staff from each center received training in teaching the curriculum. A question box in each center allowed young people to raise questions anonymously. Approximately 450 students (about 90\% males and $10 \%$ females) between the ages of 16 and 24

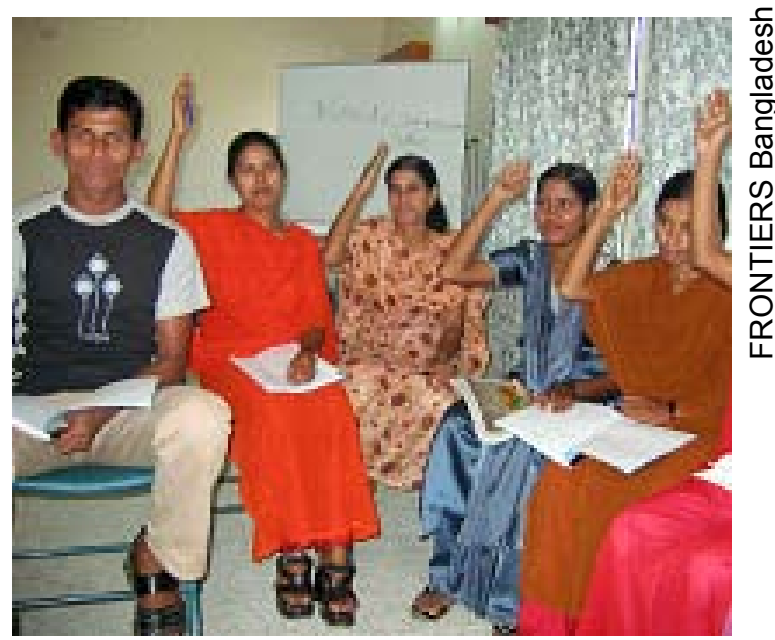

Young men and women attending the life skills training at the residential training centers.

participated in the training. Researchers used a pre-intervention survey and two post-test questionnaires to measure the effect of training on participants' reproductive health knowledge and attitudes. Qualitative data were also obtained through focus group discussions, in-depth interviews, and discussions with students and staff.

\section{Findings}

- Post-intervention scores indicated increased knowledge of reproductive health, including physiological changes during adolescence $(64 \%$ to $95 \%$ ), a woman's fertile period ( $27 \%$ to $79 \%$ ), the dual protection role of condoms ( $65 \%$ to $89 \%$ ), and knowledge of emergency contraception (42\% 
to $93 \%$ ). Knowledge about prevention of HIV also increased significantly (see Figure).

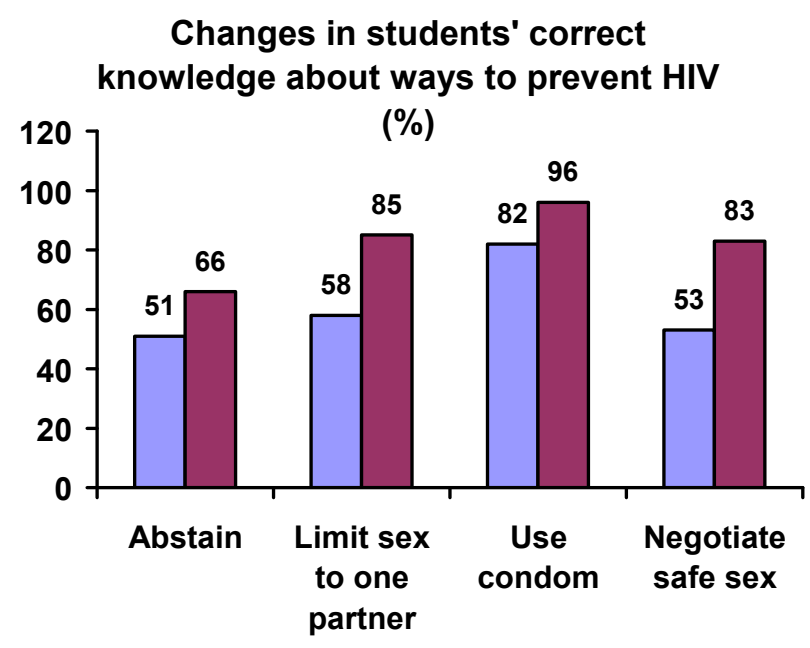

$\square$ Pre-intervention $\square$ Post-intervention

- The curriculum also had a positive impact on students' knowledge and attitudes. For example, the proportion of students who believe that menstruation is not a disease increased from 58 percent to 93 percent. Knowledge of life skills also improved, including how to avoid pre-marital sex and averting peer pressure to visit commercial sex workers.

- Both quantitative and qualitative data showed that the curriculum had cleared up a number of reproductive health "myths" identified through in-depth interviews and literature searches. For example, misconceptions about the routes of sexually transmitted infections decreased by 30 percent.
- Teachers appreciated the comprehensiveness of the training package, especially the practicum portion of the training. Students evaluated teachers positively on their knowledge, clarity, and friendliness.

\section{Utilization}

- Based on the success of the curriculum in the five pilot sites, the Ministry of Youth and Sports introduced the reproductive health curriculum into the remaining 42 residential training centers using a slightly revised curriculum. They plan to implement the training into the nonresidential centers as well.

\section{Policy Implications}

- The study findings suggest that reproductive health can be integrated into a variety of educational settings in Bangladesh. The curriculum may be more effective among older students, who have a greater practical need for the information.

March 2007

Source: Rahman, Laila et al. 2006. "Scaling up a reproductive health curriculum in youth training courses," FRONTIERS Final Report. Washington, DC: Population Council. See also: Bhuiya, Ismat et al. 2004. "Improving adolescent reproductive health in Bangladesh," FRONTIERS Final Report. Washington, DC: Population Council. Available on our website at www.popcouncil.org/frontiers/finalreports. html or by e-mail: frontiers@pcdc.org

This publication is made possible by the generous support of the American people through the United States Agency for International Development (USAID) under the terms of Cooperative Agreement No. HRN-A-00-98-00012-00. The contents are the responsibility of the FRONTIERS Program and do not necessarily reflect the views of USAID or the United States Government. 